\title{
Development and Piloting of Ascariasis Surveillance System of Children in Sri Lanka
}

\author{
Lahiru S. Galgamuwa*1, Devika Iddawela ${ }^{1}$ and Samath D. Dharmaratne ${ }^{2}$ \\ 'Department of Parasitology, Faculty of Medicine, University of Peradeniya, Peradeniya, Sri Lanka; ${ }^{2}$ Department of Community \\ Medicine, Faculty of Medicine, University of Peradeniya, Peradeniya, Sri Lanka
}

\section{Objective}

Designing, developing and Piloting an Ascariasis surveillance system of children to determine factors associated with their variations in Sri Lanka.

\section{Introduction}

Ascariasis is one of the most common intestinal nematode infections caused by Ascaris lumbricoides, especially in the tropics and subtropics where warm, wet climates favor year-round transmission of infection(1). Humans become infected by ingesting infective ascaris eggs in contaminated food, water or from hands that have become faecally contaminated and can cause reduced physical fitness, growth retardation, and respiratory and gastrointestinal problems(2). The highest morbidity is found in children, especially in those with a high worm burden(3). To identify high risk areas for intervention, it is necessary to understand the effects of climatic, environmental and socio-demographic conditions on A. lumbricoides infection(4). In Sri Lanka, although ascariasis was the commonest intestinal parasitic infection among children, information about associated factors and current health impact is insufficient. Therefore, this study was designed to develop and pilot an Ascariasis surveillance system among children in Sri Lanka.

\section{Methods}

Cross-sectional survey data of 547 study participants in the Central province in Sri Lanka were used to analyze associations between Socio - environmental data and A. lumbricoides infection, from June 2012 to April 2013. Single-stool samples were collected from each and every child to investigate A. lumbricoides infection and anthropometric measurements were taken to calculate height- forage (HAZ), weight-for-age (WAZ) and weight-for-height (WHZ) to determine stunting, underweight and thinness respectively.

\section{Results}

547 children with a mean age $6.0(\mathrm{SD} \pm 3.2)$ years was examined. Multivariate logistic regression module identified Shared toilet facilities, live in attached houses, de-worming before $6-12$ months period and before 12 months as the most important independent risk variables of all independent variables considered ascariasis. Drinking treated water, eating unclean fruit, hand washing with soap after defecation and before a meal was not statistically significant in the analysis. There was no statistically significant association between nutritional status and ascariasis.

\section{Conclusions}

The identified factors will be used in the establishment of the Ascariasis surveillance system among children in Sri Lanka.
Risk factors associated with ascariasis in Sri Lanka in 2012-2013

\begin{tabular}{|c|c|c|c|c|}
\hline Variables & Catagories & OR & $95 \%$ CI & P \\
\hline Types of dwelling & Detached houses(a) & 1 & 1 & 1 \\
\hline & Attached houses & 2.37 & $1.24-4.50$ & 0.008 \\
\hline Toilet facility & Separate(a) & 1 & 1 & 1 \\
\hline & Shared & 1.82 & $1.15-2.84$ & 0.010 \\
\hline De-worming period & $<3$ month(a) & 1 & 1 & 1 \\
\hline & $3-6$ months & 2.49 & $0.86-7.20$ & 0.090 \\
\hline & $6-12$ months & 4.89 & $1.98-12.07$ & 0.001 \\
\hline & $>12$ months & 10.95 & $4.87-24.62$ & $<0.001$ \\
\hline
\end{tabular}

(a) Reference category $\mathrm{p}<0.05$ significant $\mathrm{OR}=$ odds ratio $\mathrm{CI}=$ confidence interval $\mathrm{P}=\mathrm{p}$ value

\section{Keywords}

Ascariasis Surveillance; children; Sri Lanka

\section{Acknowledgments}

We are thankful to medical authorities, welfare officers and all the children and their parents/guardians who have voluntarily participated in this study.

\section{References}

1.Bethony J, Brooker S, Albonico M, Geiger SM, Loukas A. Soiltransmitted helminth infections: ascariasis, trichuriasis, and hookworm. Lancet 2006 May 6;367:1521-32.

2. De Silva NR, Chan MS, Bundy DA. Morbidity and mortality due to ascariasis: re-estimation and sensitivity analysis of global numbers at risk. Trop Med Int Health. 1997 Jun;2(6):519-28.

3. Xu LQ, Yu SH, Jiang ZX, Jyang JL, Lai CQ, Zhang XJ, Zheng CQ. Soil-transmitted helminthiases: nationwide survey in China. Bull World Health Organ. 1995;73(4):507-13.

4. Brooker S, Clements AC, Bundy DA. Global epidemiology, ecology and control of soil-transmitted helminth infections. Adv Parasitol. 2006;62:221-61.

*Lahiru S. Galgamuwa

E-mail: lahiruahs@yahoo.com 